\title{
JUVENTUDES FLEXÍVEIS NA AMAZÔNIA BRASILEIRA: INCERTEZAS DO SÉCULO XXI
}

Adalberto Carvalho Ribeiro(*)

O objetivo deste trabalho é fazer reflexões sobre juventudes e fenômenos presentes no século XXI realizando destaque empírico especial para compreender percepções de juventudes universitárias populares da Amazônia setentrional brasileira. A categoria juventudes tem sido de difícil enquadramento analítico, mas a literatura aceita que processos de individualização dos jovens estariam em curso desde a viragem do século XX.

As questões de partida são: - O que a literatura vem apontando quantos aos fenômenos do século XXI que atingem as juventudes?; - Quais as percepções de juventudes universitárias populares sobre questões específicas que podem lhes afligir?

O desenho metodológico faz inicialmente uma revisão breve do quadro teórico e tem como procedimento a Estatística da pesquisa empírica, de cunho quantitativo, portanto. Foram aplicados 59 questionários on-line para jovens universitários de uma universidade federal localizada na região norte do Brasil. Eles pertencem a quatro cursos de licenciaturas e por essa razão estão sendo denominados de "juventudes populares". Sabe-se que são nestes cursos, predominantemente, que os filhos de trabalhadores passaram a ter acesso ao ensino superior público brasileiro, de maneira massiva.

Dentre as quatro turmas pesquisadas, duas são de estudantes do curso de Pedagogia referentes aos anos de 2018 e 2019, tendo-se assim uma turma de calouros. Na turma 2018 são 45 estudantes. Na de calouros 51 estudantes. A terceira turma é do curso de Ciências Biológicas do ano de 2017 com 27 alunos e a quarta do curso de Física, ano 2019, calouros, e com 35 alunos. O universo total é de 158 estudantes para as 4 turmas e a amostra do estudo se refere a $37.3 \%$ do total.

A média de idade do grupo pesquisado é de 22 anos o que atende aos critérios da Secretaria Nacional de Políticas de Juventude e do Conselho Nacional de Juventude do governo brasileiro, critério que é de 15 a 29 anos para a população considerada jovem no país.

\footnotetext{
${ }^{(*)}$ Realizou estágio pós-doutoral em educação no Instituto de Educação da Universidade de Lisboa/Portugal, doutor em Ciências pelo NAEA/UFPA, professor e pesquisador vinculado ao Departamento de Educação da Universidade Federal do Amapá/UNIFAP, Macapá, Amapá. E-mail adalb.cr@gmail.com . ORCID: http://orcid.org/0000-0002-5039-7179
} 
O trabalho está dividido em 4 seções incluindo esta introdução e as considerações gerais. $\mathrm{Na}$ segunda seção faço reflexões sobre o panorama conceitual da categoria juventudes e interlocução com vários especialistas desse campo do saber. Na terceira, revelo os achados de campo e as percepções das juventudes universitárias populares da Amazônia brasileira, estudantes de licenciaturas, momento em que se verifica o que eles "acham" sobre o perfil das juventudes atuais, da sociedade de hoje, das cobranças externas que podem sentir sobre si, como a pressão externa poderia diminuir e, inclusive, o que pensam sobre o futuro profissional deles e das reformas políticas que vem ocorrendo na sociedade brasileira.

\section{PANORÂMICA CONCEITUAL: JUVENTUDES NO SÉCULO XXI - INCERTEZAS E FLEXIBILIDADE}

Como diria Bourdieu (1983): “A juventude é apenas uma palavra”.

Utilizo aqui o termo "juventudes" a exemplo de outros pesquisadores (PAIS, 1993; ALVES, 2008; ABRAMOVAY; CASTRO; WAISELFISZ, 2015; NUNES, 1968; DAYRELL, 2003; SPOSITO; TARÁBOLA, 2017) considerando que a noção conceitual juventude não se deixa facilmente submeter aos constructos teóricos ou lógicas científicas. Uma das razões é que o próprio objeto de estudo - os jovens - vive em plena movimentação buscando se adaptar às mudanças do mundo, em especial, me parece, a do mundo do trabalho.

“Construir uma definição da categoria juventude não é fácil, principalmente porque os critérios que a constituem são históricos e culturais" (DAYRELL, 2003, p. 41). Foi a partir do século XIX e meados do século XX que a noção conquistou espaço nas discussões científicas e na agenda pública (SOUZA; PAIVA, 2012), embora variando de um país para outro.

Juventude nunca foi um conceito dado e acabado, mas sim fruto de uma histórica representação específica dessa população, realizada seja no âmbito da comunidade científica, seja pelos formuladores de política públicas, ou no âmbito do senso comum. Não por acaso, a Organização das Nações Unidas para a Educação, a Ciência e a Cultura (UNESCO), não ficou de fora dessas preocupações e incorporou que o termo juventude deve considerar fatores relacionados a intensas transformações biológicas, psicológicas, sociais e culturais, que variam de acordo com as diferentes classes sociais, culturas, épocas, etnias, gênero, dentre outros aspectos determinantes (UNESCO, 2004 apud SOUZA; PAIVA, 2012).

Alves (2008), em relação à "invenção" da juventude, fez um balanço com base em vários autores (alguns deles: GALLAND, 1991; WALLACCE; KOVATCHEVA, 1998; MAUGER, 1994; 
DUBET, 1996; PAIS, 1993) sobre questões controversas que têm dividido os sociólogos da juventude.

Para uns, a juventude como idade de vida sempre existiu (GALLAND, 1991); para outros, “a juventude é socialmente construída e o seu aparecimento é um produto histórico da modernidade (CRUZ et al. 1984; WALLACE; KOVATCHEVA, 1998; DUBET, 1996; PAIS, 1993)", (ALVES, 2008, p 17).

Será no limiar do século XIX, que problemas referentes a "delinquência, imoralidade, prostituição, exploração econômica" vinculados ao jovem operariado ou filho de operário, que a construção social da juventude comportaria, em si, uma "marca de classe". Esta é uma referência importante porque nem sempre foi assim e porque os jovens aqui estudados oriundos da periferia do Brasil e filhos de segmentos pobres da sociedade, carregam também essa marca, como se verá adiante. Com a modernidade, portanto, "Juventude e problemas sociais são, assim, duas expressões que passam a ser indissociáveis e a integrar os discursos científicos, políticos e do senso comum" (ALVES, 2008, p. 24).

Assim é que estou de acordo com Nunes (1968, p. 85-86), que já se referia à juventude como uma constelação de "meios sociais juvenis" e defendia a existência não de uma, mas de várias juventudes: uma ou mais juventudes burguesas, uma ou mais juventudes operárias. “Ora, é precisamente nesta clivagem entre a unidade da juventude, por um lado, e a sua diversidade, por outro, que radica uma das principais diferenças entre as várias teorias da sociologia da juventude" (ALVES, 2008, p. 31). Constelação de meios sociais juvenis e a ideia de várias juventudes são interpretações mais apropriadas, especialmente para os dias atuais.

Ao compilar teoricamente a questão da juventude Alves (2008 cita PAIS, 1993, p. 37) mostra o agrupamento das várias teorias da juventude em torno de duas grandes correntes: a) a geracional e b) a classista.

A partir da década de 1990, surge um conjunto de trabalhos (ROBERTS, 1995, 1996; FURLONG; CARTMEL, 1997; EGRIS ${ }^{1}$, 2001; LAGRÉE, 2002), cuja filiação teórica impossibilita a sua inscrição quer na corrente geracional quer na classista. "O que une todos estes autores é, por um lado, a constatação de que as experiências de vida dos jovens se alteraram profundamente, nas duas últimas décadas" (ALVES, 2008, p. 33).

\footnotetext{
${ }^{1}$ EGRIS é a sigla que designa o European Group for Integrated Social Research. 
Esses estudiosos perceberam o surgimento de um novo fenômeno: o "prolongamento da juventude". De fato, há um consenso generalizado entre os sociólogos da juventude de que o prolongamento da juventude vem ocorrendo nas sociedades ocidentais, ainda que alguns refiram que ele não se desenrola de uma forma homogênea nem linear em todos os países (WALLACE; KOVATCHEVA, 1998; CAVALLI; GALLAND, 1995; VALLÉS, 1999). Outros (KRUGER, 1994, GALLAND, 1988) chamam a atenção para a forma diferenciada como ele ocorre quando a noção de juventude, como categoria social homogénea, é substituída por uma outra que faz ressaltar a sua heterogeneidade interna. E outros ainda (DUBET, 1987, JONES, 1995, PAIS, 1993, MAUGER, 1994), referem que há distinção conforme a origem de classe.

É que a tese do prolongamento da juventude só faz sentido sociológico quando analisada à luz da teoria do curso de vida que elegeu como objeto de estudo "as sequências de transições socialmente reconhecidas”, os acontecimentos biográficos.

A tese do prolongamento da juventude se baseia em vários fenômenos (acontecimentos biográficos) mais recentes: a) aumento generalizado da idade em que os jovens dão por concluída a sua formação escolar, b) demora na entrada no mundo do trabalho, c) saída da casa dos pais prorrogada, d) compromissos conjugais tardios, e) reprodução de filhos adiada com f ) prolongamento da condição de genitores.

No Brasil, a exemplo de outros fenômenos (econômicos, educacionais) poder-se-ia caracterizar o prolongamento da juventude como um fenômeno tardio, porém com reflexos muito peculiares em relação as diversas regiões nacionais. Me parece ser esse o caso. Por exemplo, na região norte do país as juventudes amazônidas (embora elas sejam mais vinculadas, de um modo geral, aos extratos socioeconômicos populares), contraem formas de compromissos conjugais não só mais cedo como em maior número se comparadas aos jovens da região sudeste, assim como têm filhos também mais cedo (RIBEIRO; ALVES, 2018a; RIBEIRO; ALVES, 2018b).

Uma questão importante que tem me ocorrido: qual seria um traço marcante e comum, das juventudes do século XXI, mesmo considerando suas adversidades de origem, de cor, de credo, de região, e etc.? Se este grupo etário - 15 a 29 anos - é um dos mais exigidos nos processos de adaptação (porque passarão para a fase seguinte, a fase adulta), eu diria que a flexibilização também tomou conta de seus perfis. Este traço marcante e comum a todas elas, juventudes, ainda que com as variações clássicas, é acompanhado pelos processos de individualização - radicalizados pela competitividade - e incertezas geradas pelas mudanças sociais ocorridas desde a viragem do século XX. As mudanças no mundo do trabalho, com as reformas trabalhistas em especial mas 
também as mudanças tecnológicas nas estruturas produtivas, são as que mais impactam esse grupo etário, dentre todas as outras, me parece. Digo isso porque é recorrente a dimensão produtiva (a obtenção de alguma renda) como um componente presente nas aspirações das juventudes, em especial daquelas cujas origens sociais são os extratos socioeconômicos mais populares da sociedade. A pesquisa empírica que realizei, ainda que pontual, revela este componente que mostrarei na seção 3, dos resultados.

Em Ribeiro (2018), constatei que no ano de 2014 as juventudes universitárias da Amazônia brasileira quando consideradas as variáveis 1) "Sim, tenho um trabalho remunerado e 2) "Não trabalho e estou à procura de trabalho", somadas, o percentual de pessoas nestas duas condições era de 78\% (37,02 + 40,99, respectivamente), o que revelou condições de vulnerabilidade socioeconômica e a razão de seu forte apelo à dimensão produtiva.

Segundo Szapiro e Resende (2010, p. 43)

Vivemos uma nova era que se caracteriza pelo domínio de um pensamento liberal e pela consolidação de uma sociedade de mercado. As democracias contemporâneas vivem um grande esfacelamento das instituições coletivas, que acompanhou o acento inédito, nessas sociedades, dos valores individualistas. Esse acento inédito teve como consequência a evicção mesma do sujeito moderno. A démarche moderna, invertendo a lógica antiga em que as razões do indivíduo deviam se submeter aos interesses coletivos, produziu um fenômeno novo na história da civilização ocidental: uma sociedade de indivíduos (Elias, 1991). (grifos meus)

Eles entendem que ocorreram mudanças na condição subjetiva "desse novo sujeito da pósmodernidade", com importantes consequências em suas identidades e no projeto de sociedade. Uma das consequências em curso, de modo muito geral, estaria vinculada as "etapas da vida", ou "idades da vida".

A ideia de juventude na atualidade apresenta características muito particulares, que podem ser associadas à condição pós-moderna. Assim é que as juventudes atuais estariam marcadas pelo pensamento liberal, sendo o presente o que importa. O futuro seria tecido dia após dia, sem grandes planos ou objetivos de longo prazo de vida. Como indivíduos autônomos e livres, as ações das juventudes do século XXI seriam determinadas apenas tendo como objetivo maior a maximização de um estado de prazer (SZAPIRO; RESENDE, 2010).

É controverso afirmar, no meu entendimento, que os jovens objetivam a maximização do prazer, todavia, estou de acordo que o sujeito do século XXI não é mais o mesmo sujeito do século $\mathrm{XX}$, isto é, as juventudes da era toyotista já não são mais a mesma da era taylorista, para recolocar a 
discussão nos termos de mudanças sociológicas, e que dessa forma, há uma preponderância (ainda que não determinante) de componentes mercadológicos influenciando nas relações, decisões e percepções humanas.

Neste trabalho as juventudes que revelo pertencem a uma amostra bastante pontual de um universo muito específico. São jovens universitários da região norte do país e de sua periferia, como já referi. Eles são herdeiros do campesinato caboclo² da Amazônia - ribeirinhos - (RIBEIRO, 2017) com habitus muitos singulares, porém já tendo experimentado o hibridismo cultural (GARCIA CANCLINI, 1999; 2000; SETTON, 2012) uma vez que também afetados pelas novas mídias eletrônicas contemporâneas. Seus ascendentes acumularam poucos recursos sociais (sejam os capitais econômico, cultural, escolar e social), mas paradoxalmente os sujeitos investigados já são detentores de capital escolar (quiçá, cultural!) que os distinguem de outros jovens locais porque acessaram o ensino superior.

Referindo-se ao futuro, Pais (2006. p. 12) comenta que “[...] para muitos jovens o futuro se encontra desfuturizado - não porque esteja sob controle, mas porque se encontra (des)governado pelo princípio da incerteza”.

Acompanhando Guimaraes e Grinspun (2008) para quem a definição de juventudes é construída histórica e culturalmente, também arrisco dizer que ser jovem, na sociedade contemporânea, é vivenciar uma experiência inédita.

Se a história não se repete e os processos culturais sofrem suas devidas e necessárias alterações, também a experiência de juventude não pode ser a mesma ao longo dos anos e por isso, merece atenção e cuidados especiais no que tange à reflexão e à criação de novos conceitos de identidade (GUIMARAES; GRINSPUN, 2008)

Mamede-Neves e Vidal (s/d), pesquisadores do $\mathrm{JER}^{3}$, realizaram uma interessante pesquisa com 1.202 universitários da Pontifícia Universidade Católica, do Rio de Janeiro, (PUC-Rio), "sobre que valores e que problemas" a juventude do início do século XXI apresentava. Destacaram os autores que a pesquisa revelou, inclusive, que o público pesquisado não era formado de “praticinhas" e "playboyzinhos", apenas. Muitos jovens de extratos econômicos populares eram estudantes da PUC/Rio. Fiz esse destaque porque as juventudes aqui da Amazônia alunos de

\footnotetext{
${ }^{2}$ São descendentes de nativos da região norte e de um extrato econômico social muito peculiar denominado na literatura regional de "camponês caboclo", especificamente do caboclo ribeirinho. São filhos de agricultores, pescadores, extrativistas, trabalhadores braçais ou autônomos, de mulheres "dona de casa", pais com baixo capital escolar e cultural.

${ }^{3}$ Jovens em Rede ( Grupo JER) é um diretório de pesquisa do Departamento de Educação da PUC-Rio que há mais de 10 anos realiza pesquisas sobre a juventude universitária e a construção do conhecimento. A pesquisa aqui referenciada foi realizada de 1999 a 2001 e replicada em 2002.
} 
universidades federais, de um modo geral, têm origens sociais nos extratos mais baixos da sociedade nortista.

Importante dizer que os pesquisadores do JER, metodologicamente se inspiraram na

classificação de condutas humanas propostas por Bleger (1989), procuramos usar uma distribuição semelhante, aglutinando as respostas em torno de algumas palavraschave, classificadas segundo estivessem as respostas a elas referentes mais pertinentes ao campo individual; ao campo das relações interpessoais; ao campo sócio contextual; ao campo dos valores planetários, ou seja, relativas ao planeta terra e, finalmente, ao campo dos valores universais (MAMEDE-NEVES;VIDAL, s/d).

Os pesquisadores da PUC-Rio seguiram, assim, uma hierarquia de valores e problemas em uma escala do mais próximo para o mais distante. Os resultados implicaram para uma "preponderância da dimensão social".

Procurando saber de que valores esses jovens falavam, por ordem de maior incidência encontramos: profissão, estabilidade econômica, relações afetivas, sucesso e prestígio, ter personalidade, seguidos (com menor incidência) de cidadania, família, liberdade, individualismo e, também, felicidade e melhoria de vida.

Quando se referiam a problemas da juventude, mencionavam, com maior incidência, violência, desemprego e mercado de trabalho (escasso), drogas, dificuldade financeira e incerteza econômica, má qualidade de vida, situação do país, preconceito para com os jovens (MAMEDE-NEVES;VIDAL, s/d p. 3). (Grifos originais).

A citação acima revela não só a preponderância da dimensão social, mas nesta, a maior incidência de valores com maiores recorrência nas respostas como profissão, estabilidade econômica, relações afetivas, sucesso e prestígio, etc. No aspecto problemas as maiores incidências de respostas foram violência, desemprego e mercado de trabalho, drogas, etc. Sublinhei palavraschave que revelaram respostas que se associam ao mundo do trabalho porque estas respostas apontam para a importante influência da questão econômica na vida das juventudes conforme já comentei no início deste artigo.

Minhas reflexões sobre as juventudes, tanto no quadro conceitual quanto no empírico, mesmo tendo como recorte de terreno as juventudes universitárias da Amazônia brasileira, têm me levado a inferir algumas considerações, a seguir.

As juventudes não são completamente suscetíveis ao cálculo racional para tomar suas decisões em relação a entrada na vida adulta. As condições atuais de incerteza e risco em que vivem as levam a jogar com uma série de possibilidades. Os clássicos "acontecimentos biográficos" como 
idade, formas de matrimônios, inserção profissional, filhos, prolongamento dos estudos e independência habitacional, por exemplo, não são as condições determinantes para a entrada na vida adulta, nem em conjunto, nem isoladamente. Um dos aspectos mais importantes para a entrada neste estágio decisivo na vida é a estabilidade no emprego. Ou seja, tem a ver com as diversas formas de inserções profissionais ${ }^{4}$ e seus processos. É quando o jovem compreende que (no emprego) está estável, que ele tem como planejar o futuro com segurança minimizando riscos, aí resolve deixar a juventude para atrás e entrar na vida adulta em definitivo. Este momento, o da estabilidade no emprego, tem grande influência na transição de um estágio para outro. Todavia, considerar-se estável no emprego implica em avaliação subjetiva por parte do sujeito a ponto de ele sentir-se bem na ocupação que desenvolve com um mínimo de grau de satisfação pessoal. A estabilidade no emprego, portanto, tem a ver com critérios objetivos e subjetivos - quando o indivíduo considera questões salariais, estabilidade, status, grau de satisfação e etc., que varia de pessoa para pessoa.

Dessa maneira, juventudes não podem mais ser caracterizadas somente como "efeito ioiô" como disse Pais (1993). Considerando a natureza conceitual e empírica do fenômeno analisado, o efeito sempre dialético, pode e deve ocorrer com o ioiô em gradações desgovernadas cuja velocidade não prevê gerenciamento pelo "jogo da vida".

Esta movimentação desgovernada do fenômeno implica em uma consequência muito importante e, em um dos momentos mais sublimes das juventudes que é a inserção profissional (ao que parece, a juventude vai ser concluída muito mais com a estabilidade profissional do que com a inserção propriamente dita).

O fenômeno juventudes, conceitual e empiricamente, é elástico e plástico de modo que, dada essa natureza, ele pode se movimentar de vários modos em interregno de tempo cada vez menor a se considerar as características da sociedade atual que deixou para trás de vez a taylorização e entrou em uma época que é mais que não-linear, mais que toyotista, mais que incerta, mais que precária, ela é "instantaneamente imprevisível", ou seja, a cada instante seguinte ela pode se apresentar de outro modo, pois ela se apresenta também de modo flexível.

Quanto às juventudes da Amazônia brasileira - uma parte delas objeto de minhas reflexões neste trabalho - com singularidades particulares, tenho a considerar que 1) a juventude popular da

\footnotetext{
${ }^{4}$ A inserção profissional se dá de várias maneiras e formas, de modo que faz muito mais sentido tratar a noção também no plural (a exemplo de juventudes). Aliás, estas duas categorias guardam vínculos conceituais importantes porque o objeto empírico delas têm nos jovens fartos fenômenos interligados.
} 
Amazônia está em franco processo de hibridização cultural (SETTON, 2012) nos termos de processos de influências recíprocas porque seus habitus e capital cultural foram reconfigurados completamente e continuam a sê-los. Ela é herdeira de uma cultura oral e a passagem para a cultura escrita, assim como o acesso à escola, causou-lhe uma verdadeira revolução em suas trajetórias de vida, tornando-os indivíduos completamente distintos dos seus ascendentes - o camponês caboclo, 2) a minha suspeita é que as mudanças no mundo produtivo, especialmente no momento da inserção profissional das juventudes, causaram sim mudanças nas formas de socialização contemporânea porque a componente tecnologia e as exigências "de e para" um trabalhador flexível impactou na formação educacional deles, inclusive tornando-os mais suscetíveis aos processos de individualização e de competitividade.

\section{JUVENTUDES UNIVERSITÁRIAS NA AMAZÔNIA BRASILEIRA: FLEXIBILIDADE E INCERTEZAS - PRIMEIROS APONTAMENTOS}

Os dados a serem mostrado abaixo é um recorte de uma pesquisa maior que tratou das percepções das juventudes quando se fez um conjunto de perguntas em sua maioria fechadas e algumas abertas.

Na visão vygotskyana, a percepção não apresenta um caráter estático, definitivo e imutável, pelo contrário, segue se desenvolvendo de forma dinâmica na medida em que as experiências de mediação e de interação social entre os indivíduos, e entre o indivíduo e seu meio histórico-cultural se multiplicam, se amalgamam e se sofisticam. Trata-se da concepção denominada de históricocultural (VYGOTSKY, 1994).

Vygotsky concluiu que embora presente nos adultos, nas crianças e nos animais a percepção apresenta grandes variações em sua qualidade e complexidade. Ele assim, forjou um conceito amplo da categoria percepção, compreendendo-a como fenômeno fisiológico, psicológico e cultural.

[..] eu entendo que o mundo não é visto simplesmente em cor e forma, mas também como um mundo com sentido e significado. Não vemos simplesmente algo redondo e preto com dois ponteiros; vemos um relógio e podemos distinguir um ponteiro do outro. Alguns pacientes com lesão cerebral dizem, quando veem um relógio que estão vendo alguma coisa redonda e branca com duas pequenas tiras de aço, mas são incapazes de reconhecê-lo como um relógio; tais pessoas perderam seu relacionamento real com os objetos. Essas observações sugerem que toda percepção humana consiste em percepções categorizadas ao invés de isoladas (VIGOSTSKY,1994, p. 44). 
As juventudes aqui pesquisadas, neste ano de 2019, têm origem social nos extratos mais baixos da sociedade. Seus pais detêm, em média, pouco capital escolar, assim como exercem profissões populares, "sem prestígio".

No tocante às perguntas propriamente ditas, perguntei se consideram que o jovem atualmente tenha se tornado ainda mais individualista. Os quesitos para as respostas constavam de variáveis que iam de uma escala do "Não concordo" ao "Concordo 100\%", em relação ao enunciado.

As respostas apontaram no seguinte sentido: 6\% não concordaram. Para estes, suas percepções é de que as juventudes não estão mais individualistas que antes. $13.7 \%$ concordou $100 \%, 35.5 \%$ concordou $75 \%$ com o enunciado. Os que concordaram $50 \%$ com o enunciado foram $36.5 \%$ e $8.4 \%$ concordou $25 \%$. As respostas indicam (quando somo $13.7 \%+35.5 \%=49.2 \%$ ) que as percepções estão em uma tendência em que, aproximadamente, a metade dos jovens pesquisados aceitam que as juventudes atuais estão mais individualistas. Um grupo menor de $14.4 \%$ ( $6 \%+8.4 \%$ ) estaria em uma tendência de não aceitar o enunciado. As mudanças que ocorreram e que vem ocorrendo na sociedade e as experiências já realizadas pelos universitários pesquisados os colocam em uma leitura bastante razoável da realidade.

Quando perguntei sobre uma sociedade atual mais competitiva, as respostas é de que concordam em algum grau. Não houve nenhuma resposta discordando do enunciado. 68\% concordaram $100 \%$ que a sociedade atual é mais competitiva, $26 \%$ concordaram em $75 \%$ que ela é mais competitiva, $4,5 \%$ apontaram $50 \%$ e apenas $1.5 \%$ indicaram $25 \%$. Portanto, nesta variável as juventudes que pesquisei estão em clara tendência de aceitar o enunciado: são $94 \%(68.1 \%+25.9)$. É uma percepção clara, objetiva, de quem, a meu ver, percebe que os recursos a serem alcançados exigem mais esforços, atualmente, para serem adquiridos.

Perguntei se se sentiam pressionados pelas exigências do mundo atual e de onde mais partia essa pressão. $3.8 \%$ respondeu que não se sente pressionado enquanto $67.5 \%$ respondeu que se sente muito pressionado. $27.7 \%$ respondeu razoavelmente e apenas $1.4 \%$ disse que se sente pouco pressionado.

A pressão a que se referem partiria deles próprios em 39\% dos casos enquanto para $45.5 \%$ a pressão vem da sociedade como um todo. Mas 14\% apontou pressões da família e $1.5 \%$ pressão dos professores. 
Quando perguntados o que fariam para aliviar a pressão que sentem $16.3 \%$ respondeu que iria morar sozinho/a, 4.6\% moraria como amigos/as, $74 \%$ indicou que obtendo emprego enquanto $5 \%$ preferiria morar com o namorado/a.

As respostas acima indicam que a pressão social existe sobre a maioria dos jovens e que ela vem de toda a sociedade. A forma que eles encontrariam para fugir da pressão seria obtendo um emprego. As respostas, portanto, revelam que a variável renda, a questão econômica, é muito presente na vida dessas juventudes. Sendo elas de origem social modesta estão mais suscetíveis e abertos ao mundo do trabalho. Na verdade eles necessitam de algum tipo de renda para suprirem necessidades várias que vão desde a permanência na universidade até pequenos itens de consumo.

Perguntei ainda se pretendiam obter alguma renda enquanto estudavam, sobre seus futuros profissionais e sobre as reformas em andamento neste momento no Brasil capitaneadas pelo governo central. $81 \%$ deles respondeu que pretende obter alguma renda enquanto estudam, $4 \%$ não pretende e $15 \%$ não pretende porque prejudicaria os estudos. Quanto ao futuro profissional 13\% acredita que em 6 meses estará empregado após a formatura, 12\% acredita que em 1 ano, enquanto em até 2 anos 2\% acredita que encontrará emprego. Entretanto, a percepção de $73 \%$ é de que “Tudo é muito incerto, não tenho como estimar".

A percepção deles quanto às reformas em andamento tocadas pelo governo brasileiro revela que $15 \%$ está otimista pois acredita que haverá mais empregos, $25 \%$ está pessimista porque acha que haverá menos empregos, 30\% "Não tenho uma ideia clara, mas estou muito preocupado", $28.5 \%$ não tem uma ideia clara mas está razoavelmente preocupada, e, apenas $1.5 \%$ não está preocupada mesmo não tendo uma ideia clara do assunto.

Desse último conjunto de perguntas as variáveis respondidas apontam que as juventudes universitárias pesquisadas, de fato, passam por algum tipo de necessidade/privação porque mais de $80 \%$ pretende obter renda mesmo enquanto estudam, que a incerteza é um componente presente em suas vidas quanto ao planejamento futuro e que mais da metade não está otimista quanto às reformas que estão na pauta do dia do governo federal, consequentemente estão muito preocupados com seus futuros. Por outro lado, as variáveis indicaram que sobre as reformas $60 \%$ não tem uma ideia clara sobre esses temas.

Finalmente, das perguntas abertas feita a eles a que interessa para o escopo deste trabalho: o que é ser jovem? Utilizando como critério o destaque para palavras-chave com maior incidência de respostas, saltaram as seguintes nas variadas respostas: busca de identidade, escolhas/decisões, ideais/objetivos, liberdade/responsabilidade, sonhos, amadurecimento, emprego, crescer, 
experiência, conhecimento, dias melhores, descobertas, novas experiências, descobrimento, ultrapassar limites, extravasar, aprender, batalhar, independência, oportunidade, maturidade, alcançar metas, inconsequência.

Estas palavras chaves revelam, na minha análise, duas dimensões: a primeira que manifesta o lado romântico da juventude onde as descobertas, a inconsequência, as novas experiências, sonhos, limites a serem ultrapassados, a intensidade, estas noções, destacam um modo de encarar esta fase da vida aproveitando o momento de ser jovem, dando-se ao direito de "curtir a vida".

A segunda que manifesta o lado real da juventude, as preocupações com as transformações em curso e com as cobranças mais recorrentes da sociedade onde as escolhas, decisões, objetivos, responsabilidades, crescimento, conhecimento, emprego, oportunidades, amadurecimento, metas, independência, estas outras noções, revelam uma percepção mais imediata dos acontecimentos da vida.

O grupo pesquisado, portanto, mostra que mesmo sendo jovem e dando-se ao direito de curtir a vida não consegue se desvanecer das pressões da competitiva sociedade atual. Se fizermos uma compilação de todo o conjunto de respostas advindas nas variáveis destacadas neste trabalho é possível admitir que elas, as respostas entre si, estão bastante coerentes. Há uma coerência na linha de raciocínio nas respostas das juventudes pesquisadas, assim como suas respostas guardam relação com as luzes que emanam da literatura consultada na seção anterior.

Em resumo, na percepção do grupo pesquisado,

1) Os jovens, de um modo geral, estão mais individualistas;

2) A sociedade atual é mais competitiva;

3) Eles se sentem muito pressionados;

4) A pressão parte da sociedade como um todo, mas os jovens pesquisados se cobram muito também;

5) A forma de aliviar a pressão seria obtendo emprego para a grande maioria deles;

6) Este grupo tem necessidade de obter renda mesmo durante seus estudos;

7) Quanto ao futuro profissional eles percebem muita incerteza pela frente;

8) E quanto às reformas do governo federal, ainda que a maioria não tenha ideia clara dos temas, estão pessimistas e muito preocupados com o futuro; 


\section{CONSIDERAÇÕES FINAIS}

O trabalho teve como objetivo fazer reflexões sobre as juventudes e os fenômenos presentes no século XXI realizando destaque empírico pontual para compreender percepções de juventudes universitárias populares da Amazônia setentrional brasileira.

Os achados de campo me levaram a afirmar que as juventudes pesquisadas, os jovens com média de 22 anos de idade, universitários de uma universidade de periferia da Amazônia brasileira, acreditam que, de um modo geral, as juventudes estão mais individualistas em uma sociedade cada vez mais competitiva. Ao se sentirem pressionados acreditam que boa parte das cobranças partem da sociedade como um todo e, prioritariamente, obteriam um emprego como forma de aliviar essa pressão.

Por serem juventudes pertencentes a segmentos sociais populares, eles têm desejos de trabalhar de alguma forma, mesmo durante os estudos universitários. Estão muito afetados por sentimentos de incertezas quanto ao futuro mercado profissional, assim como estão, em maioria, pessimistas e muito preocupados com o futuro de um modo geral ao se posicionarem sobre as mudanças que a sociedade brasileira vem passando com as reformas do governo central.

Os achados de campo estão em perfeita vinculação com a literatura especializada da área. Processos de individualização das juventudes, universalmente, estão bem caracterizados nos estudos teóricos, como mostrei. Fenômenos como incertezas, mudanças muito rápidas no paradigma produtivo, prolongamento das juventudes, e mais recentemente o que estou chamando de flexibilidade, estão presentes nas vidas dos jovens da atualidade, ainda que guardadas as devidas singularidades a depender de regiões, extratos sociais, enquadramento cultural, e etc.

O termo flexibilidade deriva, de fato, da força imperativa que tem a questão econômica na vida das pessoas, e no caso dos jovens, as novas exigências para entrada no mercado de trabalho local/global os fazem jogar, agora, com um novo conjunto de exigências e possibilidades que podem mudar a todo instante. Daí o termo "juventudes flexíveis". Não há dúvidas que a reestruturação produtiva tida como mais flexível impactou nas subjetividades das pessoas, e as juventudes foram, mais uma vez, aquelas mais afetadas. 


\section{REFERÊNCIAS}

ABRAMOVAY, Miriam; CASTRO, Mary Garcia; WAISELFISZ, Júlio Jacobo. Juventudes na escola, sentidos e buscas: por que frequentam? Brasília: Flacso-Brasil, OEI, MEC, 2015.

ALVES, Natalia. Juventudes e inserção profissional. Lisboa, Portugal: Educa, 2008.

BOURDIEU, Pierre. A juventude é apenas uma palavra. In: Questões de sociologia. Rio de Janeiro, Marco Zero, 1983.

CAVALli, A.; GALLAND, O. Youth in Europe. Social change in Western Europe. London: Printer. 1995.

CRUZ, M. B. et al. A condição social da juventude portuguesa. Análise Social, Lisboa, v. 20, n. 81-82, p. 285-308, 1984.

DAYRELL, Juarez. O jovem como sujeito social. Revista Brasileira de Educação, Rio de Janeiro, n. 24, p. 40-52, set./dez. 2003.

DUBET, F. La galère: jeunes en survie. Paris: Fayard, 1987.

DUBET, F. Des jeunesses et des sociologies. Le cas français. Sociologie et sociétés, Paris, v. 28, n. 1, p. 23-35, 1996.

EGRIS - European Group for Integrated Social Research. Misleading trajectories: transition dilemmas of young adults in Europe. Journal of Youth Studies, Berlim, Alemanha, v. 4, n. 1, p. 101-118, 2001.

FURLONG, A.; CARTMEL, F. Young people and social change. Individualization and risk in late modernity. Buckingham: Open University Press. 1997.

GARCIA-CANCLINI, Nestor. Culturas Híbridas. São Paulo, Edusp, 1999.

Noticias recientes sobre la hibridación. In: Revista Transcultural de Música. 7ISSN:1697-0101.(texto presentado como conferencia del profesor invitado en el VI Congreso de la SibE, celebrado en Faro en julio de 2000.

GALLAND, O. Représentations du devenir et reproduction sociale: le cas des lycéens de d'Elbeuf. Sociologie du Travail, Paris, v. 30, n. 3, p. 399-417, 1988.

GALLAND, O. Sociologie de la jeunesse. L'entrée dans la vie. Paris: Armand Colin. 1991.

GUIMARÃES, Gilselene Garcia; GRINSPUN, Miariam Zippin. Revisitando as Origens do Termo Juventude: a diversidade que caracteriza a identidade. $31^{a}$ REUNIÃO ANUAL DA ANPED. Anais... GT Psicologia da Educação. Caxambu (MG): 2008. Disponível em: 〈http://www.anped.org.br/reunioes/31ra/1trabalho/GT20-4136-Int.pdf>. Acesso em: 14 fev. 2019.

JONES, G. Leaving home. Buckingham: Open University Press, 1995.

LAGRÉE, J. C. Youth and post-modernity. In: LAGRÉE, J. C. (Ed.). Rolling youth, rocking society. Paris: Unesco, 2002. p. $15-43$

KRUGER, H. La prolongation de la durée de la heunesse : un phénomène diffèrencié selon les sexes. In: MAUGER, G.; BENDIT, R.; WOLFFERSDORFF, C. (Ed.). Jeunesses et sociétés. Perspectives de la recherche en France et en Allemagne. Paris: Armand Colin, 1994. p. 78-94.

MAMEDE-NEVES, Maria Apparecida; VIDAL, Fernando. Valores e problemas da juventude pela lente de jovens. s/d. Disponível em: <https://www.maxwell.vrac.puc-rio.br/.../14483.PDFXXvmi=O4DZf2cIjuDcnBzv5j0k. Acesso em: 25 fev. 2019.> Acesso em: 14/ fev. 2019.

MAUGER, G. Les jeunes en France. État des recherches. Paris: La Documentation Française, 1994.

NUNES, A. S. Sociologia e ideologia do desenvolvimento. Lisboa: Moraes Editores, 1968.

PAIS, J. M. Culturas juvenis. Lisboa: Imprensa Nacional, 1993.

Buscas de si: expressividades e identidades juvenis. In: ALMEIDA, Maria Isabel M.; EUGENIO, Fernanda. (Orgs.). Culturas jovens: novos mapas do afeto. Rio de Janeiro: Jorge Zahar Ed., 2006. p. 07-21.

RIBEIRO, A. C. Juventudes universitárias populares na Amazônia: processos de hibridização cultural e inserção profissional. Relatório de pesquisa. Estágio de pós doutoramento. Instituto de Educação da Universidade de Lisboa. Portugal. 2018.

. Processos de formação do capital cultural e resistência de professores alunos na Amazônia Setentrional. Utopía Y Praxis Latinoamericana. Revista Internacional De Filosofía Y Teoría Social, Maracaibo-Venezuela, año: 22, n. 79, oct./dic. 2017. 
RIBEIRO, A.C; ALVES, N. Origem social e fenômenos regionais no meio juvenil popular: as insistentes desigualdades no ensino superior público brasileiro. In: CABRITO, B; MACEDO, Jussara M; CERDEIRA, Luísa. (Orgs.) Ensino superior no Brasil e em Portugal: atualidades, questões, inquietações. Educa, Lisboa. Portugal, 2018 a . p. $123-147$.

Juventudes universitárias populares e educação freireana: reflexões sociológicas. Revista Quaestio, Sorocaba, SP, v. 20, n. 2, p. 305-325, ago. 2018b.

ROBERTS, K. Youth and employment in modern Britain. London: Oxford University Press, 1995.

ROBERTS, K. Individualization and risk in Eastern and Western Europe. In: HELVE, H.; BYNNER, J. (Ed.). Youth and life management. Research Perspectives. Helsinki: Helsinki University Press, 1996. p. 226-240.

SETTON, Maria Graça J, Lazeres e práticas híbridas de cultura entre jovens na Amazônia. Sociologia da educação: revista luso brasileira, Rio de Janeiro, PUC/RJ, 2012.

SOUZA, Candida; PAIVA, Ilana Lemos. Faces da juventude brasileira: entre o ideal e o real. Estudos de Psicologia, Natal, RN, v. 3, n. 17, p. 353-360, set./dez. 2012. Disponível em: 〈www.scielo.br/epsic〉. Acesso em: 29 mar. 2018.

SPOSITO, Marília P.; TARÁBOLA, Felipe S. Entre luzes e sombras: o passado imediato e o futuro possível da pesquisa em juventude no Brasil. Revista Brasileira de Educação, Rio de Janeiro, v. 22, n. 71, p. 1-25, 2017.

VALLÉS, M. Jóvenes españoles, jóvenes europeos a las puertas del siglo XXI. In: CACHÓN, L. (Ed.). Juventudes, mercados de trabajo y políticas de empleo. Valencia: Editorial 7 i Mig, 1999. p. 119-131.

VYGOTSKY, Lev Semenovitch. Teoria básica e dados experimentais. In: MICHAEL, $C$. et al. A formação social da mente: o desenvolvimento dos processos psicológicos superiores. Tradução de José C. Neto, Luis S. M. Barreto e Solange C. Afeche. 5. ed. São Paulo: Martins Fontes, 1994. p. 25-99. (Coleção Psicologia e Pedagogia).

WALLACE, C.; KOVATCHEVA, S. Youth in society. The construction and deconstruction of youth in East and West Europe. London: Macmillan Press. 1998. 


\section{RESUMO}

O objetivo é fazer reflexões sobre as juventudes e os fenômenos presentes no século XXI destacando no quadro empírico percepções de juventudes universitárias populares da Amazônia setentrional brasileira. A categoria juventudes tem sido de difícil enquadramento analítico mas a literatura aceita que processos de individualização estariam em curso desde a viragem do século XX. As questões de partida são: o que a literatura vem apontando quantos aos fenômenos do século XXI que atingem as juventudes? Quais as percepções de juventudes universitárias populares sobre questões específicas que podem lhes afligir? A abordagem metodológica além da consulta aos interlocutores especialistas nesse campo do saber também realizou pesquisa empírica com estudantes de licenciaturas de uma universidade federal da região norte do Brasil, razão pela qual estão sendo denominados de "juventudes populares". Os resultados apontam, na literatura, consenso quanto a processos de individualização, preocupação com a dimensão social e no grupo estudado percepções para a aceitação do individualismo, competitividade, incertezas quanto ao futuro e vulnerabilidade social.

Palavras-chave: Juventudes, flexibilidade, incertezas, Amazônia.

\section{FLEXIBLE YOUTH IN THE BRAZILIAN AMAZON: UNCERTAINTIES OF THE 21ST CENTURY}

\section{ABSTRACT}

The objective is to make reflections on the youths and the phenomena present in the XXI century highlighting in the empirical framework perceptions of popular university youths of the northern Brazilian Amazon. The youths category has been difficult to analyze, but the literature accepts that processes of individualization have been underway since the turn of the twentieth century. The starting questions are: What literature has been pointing to how many of the XXI century phenomena that affect youth? What are the perceptions of popular university youths about specific issues that may afflict them? The methodological approach in addition to the consultation of specialists in this field of knowledge also carried out empirical research with undergraduate students from a federal university in the northern region of Brazil, which is why they are being called "popular youths". The results point out, in the literature, a consensus regarding the processes of individualization, concern with the social dimension and in the group studied perceptions for the acceptance of individualism, competitiveness, uncertainties about the future and social vulnerability.

Keywords: Youths, flexibility, uncertainties, Amazon.

\section{JUVENTUD FLEXIBLES EN LA AMAZONIA BRASILEÑA: INCERTIDUMBRES DEL SIGLO XXI}

\section{RESUMEN}

El objetivo es hacer reflexiones sobre las juventudes y los fenómenos presentes en el siglo XXI destacando en el cuadro empírico percepciones de juventudes universitarias populares de la Amazonia septentrional brasileña. La categoría juventudes ha sido de difícil encuadramiento analítico pero la literatura acepta que procesos de individualización estarían en curso desde el viraje del siglo XX. Las cuestiones de partida son: lo que la literatura viene apuntando cuantos a los fenómenos del siglo XXI que alcanzan las juventudes? ¿Cuáles son las percepciones de juventudes universitarias populares sobre cuestiones específicas que les pueden afligir? El enfoque metodológico además de la consulta a los interlocutores especialistas en ese campo del saber también realizó una investigación empírica con estudiantes de licenciaturas de una universidad federal de la región norte de Brasil, razón por la cual están siendo denominados de "juventudes populares". Los resultados apuntan, en la literatura, consenso en cuanto a procesos de individualización, preocupación con la dimensión social y en el grupo estudiado percepciones para la aceptación del individualismo, competitividad, incertidumbres en cuanto al futuro y vulnerabilidad social.

Palabras clave: Juventudes, flexibilidad, incertidumbres, Amazonia. 